\title{
IMPLEMENTATION OF FPC CONCEPT IN ELECTRICAL WIRE EQUIPMENT DESIGN
}

\author{
Hui Zhao ${ }^{1}$, Lixin $\mathrm{Lu}^{2}$, Limin $\mathrm{Li}^{1}$, Jun Chen ${ }^{1}$ \\ ${ }^{I}$ CIMS center, Shanghai University, Shanghai, 200072, China, Email of the first \\ author::uu8490077@126.com. ${ }^{2}$ Shanghai Feilo Co., LTD, Shanghai,200050, China.
}

\begin{abstract}
This paper introduces FPC concept, and exemplifies it with a full-automatic crimping machine developed recently, therefore proposed a new viewpoint---assembly weight.
\end{abstract}

Key words: FPC, crimping machine, assembly weight.

\section{INTRODUCTION}

Modern manufacturing includes multiple advanced methods : Virtual Manufacturing, Concurrent Engineering, Lean Production, Clean Factory, Remanufacturing, etc, all of which are devoted to solving two great challenges faced with today's enterprises: depressing cost, and raising manufacturing capability. In this case, FPC (First Product Correct) is put forth, it meets the actuality of lack of resources, and raises a higher standard of time, quality, cost, service, and environment.

FPC can be regard as successfully making at the first try, or first design and success, it was initially proposed by American Integrated Manufacturing Technology Institute, and eventually becomes an important research orientation. Focus of FPC is to turn design concept into effective goods, or to turn single small batch production into multiple volume production, with particular emphasis on continuous production. It rejects drawbacks of volume mining, volume consuming, volume abandoning in conventional economy.

Please use the following format when citing this chapter:

Zhao, Hui, Lu, Lixin, Li, Limin, Chen, Jun, 2006, in International Federation for Information Processing (IFIP), Volume 207, Knowledge Enterprise: Intelligent Strategies In Product Design, Manufacturing, and Management, eds. K. Wang, Kovacs G., Wozny M., Fang M., (Boston: Springer), pp. 224-230. 
Audiences of FPC vary from industry, government, to academy. Conventional concepts are also adopted by FPC, such as Integrated Manufacturing, Concurrent Corporation, CAD/CAPP/CAM, PDM, etc. FPC changes the ordinal manufacturing process which lacks of interactive communication. Once defect happens, the design will be transferred in time. With FPC, each department will feed back effectively before concept design, so that to achieve lower design alternation, shorter life cycle, lower cost, and first production correct.

\section{MAINFRAME OF SYSTEM REALIZATION}

Our project combines an electrical wire equipment (full-automatic crimping machine, processing electrical wire for automobile use), with embodied operational flow of FPC, and finally gains success from design to manufacturing at the first time.

As a modern managerial measure, FPC focuses on standardization of implementation, and clarity of responsibilities. Hence, we need to divide our members effectively. It is the viewpoint of FPC theory that the responsible team needn't too large, but must cross multiple departments. Corresponding teams are organized according to different production stages, and usually, that teams has a polar structure (see figure 1)

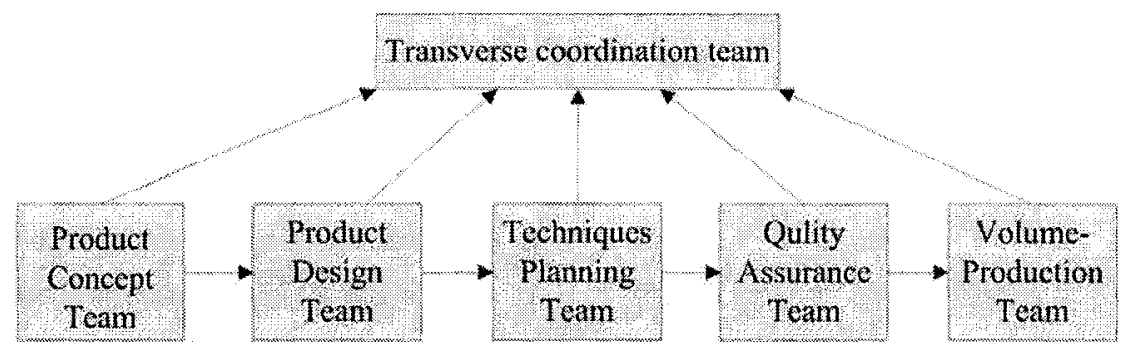

Figure 1. Structure of FPC Team

In order to optimize whole cycle of production, FPC needs to accurately define flow of output firstly, and then hand on each function branch to individual team. Each team doesn't only shoulder its own job, but also communicates immediately. Typical operation of FPC is depicted through operational flow of electrical wire manufacturing equipment in figure 2 . 


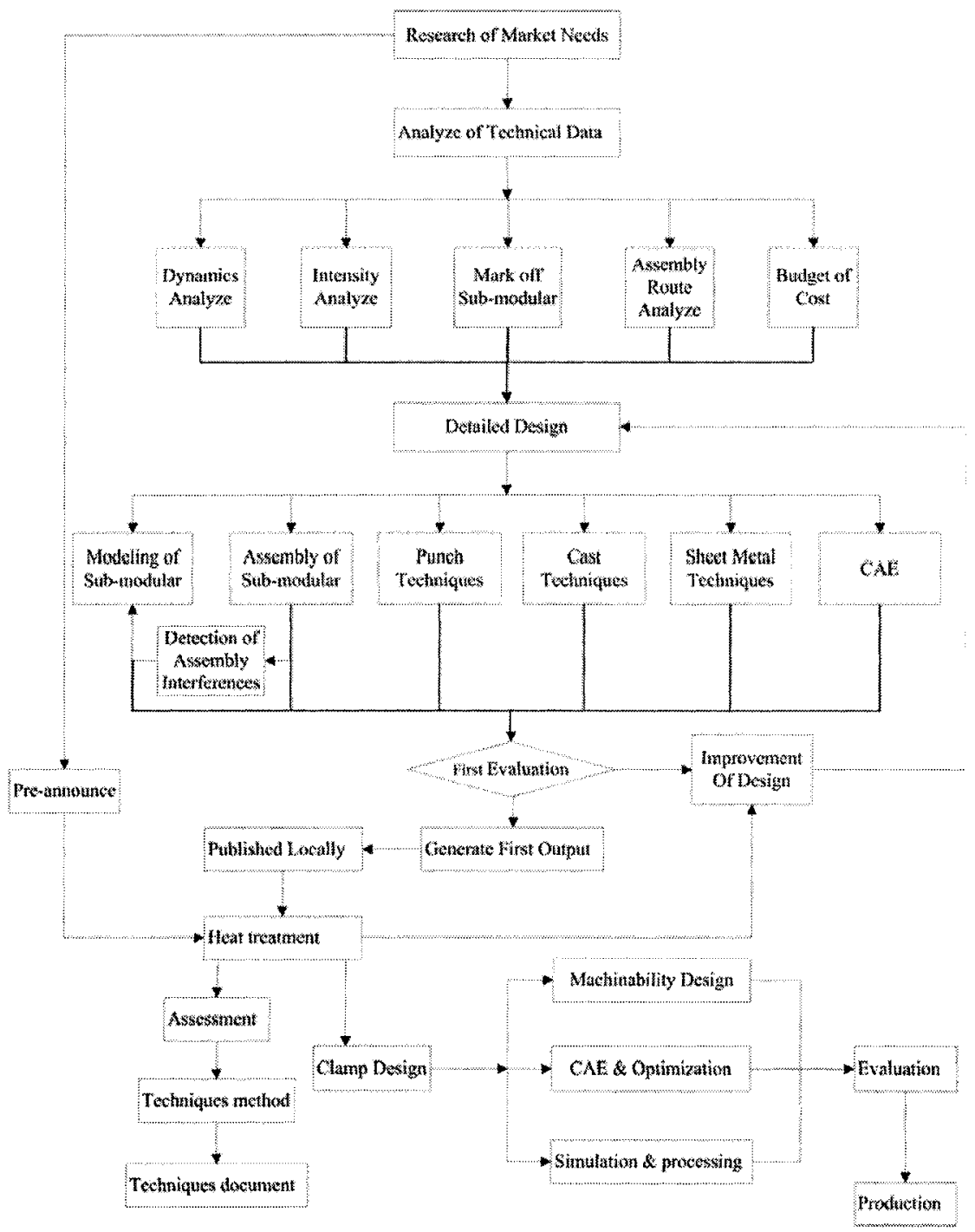

Figure 2. Operational Flow of FPC

\section{DETAILED OPERATIONAL SCHEMES}

At first, production concept team accurately orients market through fruitful marketing research, sketches out technical parameters, for example, 
cutting length of wire is $30-9999 \mathrm{~mm}$, stripping length of wire is $1.0-10 \mathrm{~mm}$, etc.Then conceives out rough assembly method, and divides relevant mechanism into modules, then plans assembly path. This full-automatic wire crimping machine can be divided into several mechanisms (see figure 3)

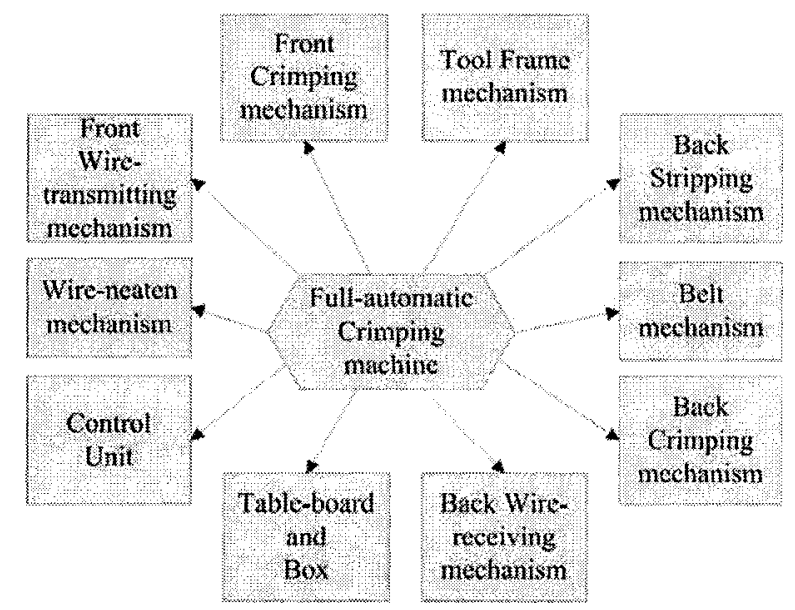

Figure 3. Mechanical Structure of Full-automatic Crimping Machine

Principle of this full-automatic crimping machine is as follows: wireneaten mechanism strains wound wire straightly, for the convenience of processing. then the wire is sending to tool frame mechanism for stripping, after stripping it is time for front crimping mechanism to crimp one end of the wire, subsequently back Wire-receiving mechanism nips the wire, and waits for stripping of the other end and rotates to have this end crimped in the back crimping mechanism, finally processed wire is sent to belt mechanism which collects all the finishing wires.

Product design team members work collaterally to set up models through powerful virtual tool (UGNX). With a information-sharing platform, they can communicate in time on material, heat treatment and so on that make product machinable and capable of assembly. Meanwhile, several design variables is defined, including intensity, rigidity, cost, $\cdots \cdots$, to compose a target function, which is finally optimized by convergent arithmetic, such as Genetic Algorithm, Ant Colony Optimization, etc. Finally, design rules come out. Each modular is made sure to be connected with whole assembly through low-cost standard elements that are easily found. Main modules are in figure 4 (Tool Frame \& Back wire-receiving mechanism).

Afterwards, techniques planning team works out technique documents, and carries on CAE analysis. for example, whether moments of inertia in 
relevant rotating component match each other, whether mechanical jaws cause noises while working $\cdots \cdot \cdots$. (As shown in figure 5)

At last, quality assurance team proceeds checking and revising, give all summarize to volume-production team for their convenience of establishing production planning.
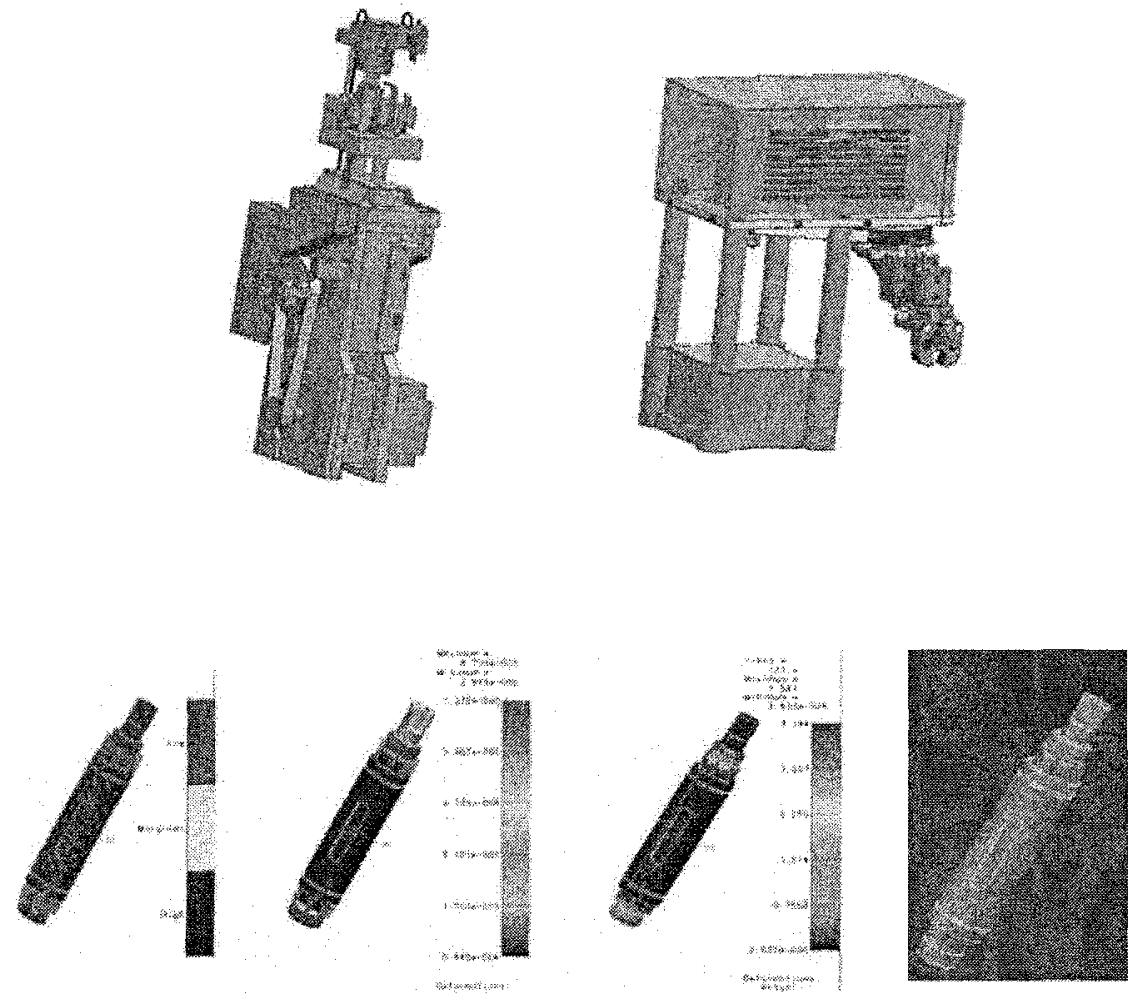

Figure 5. FEA meshing \& Displacement \& Stress \& Structural Analysis

\section{KEY TECHNOLOGY OF FPC-ASSEMBLY OF INTEGRATED PRODUCT}

Assembly is the actual embodiment of machine's function, and is also the guideline of design and manufacturing, because requirements of assembly run through the entire designs of parts. All designs are devised on the behalf of implement of assembly function. 
For that research of product in integrated manufacturing and assembly are key problems of FPC, it is necessary to consider constraints relevant to assembly manufacturing at initial stage. We should allocate different weights to different sub-assembly, place connections between sub-modules, feed back to designer of each modular to help them modify immediately, so that holistic design of machine links with every sub-modular friendly, while keeping reasonable remaining value to support reliability design.

Key weight of this full-automatic crimping machine lies in tool frame mechanism. Location of tool frame directly restricts relative positions of back stripping mechanism, front/back crimping mechanism, belt mechanism. Therefore we regard tool frame as the first weight (first consideration), and choose position of front/back crimping machine according to it. Back wirereceiving machine is the second weight for its movement area is only $58 \mathrm{~mm}$, $45^{\circ}$. Function of belt mechanism is taking finished wire from back wirereceiving mechanism; we consider it as the third weight.

As for much larger scale mechanism, we can search for an all-around optimal solution, such as simulate anneal arithmetic. This arithmetic is suitable for scale combination optimization; it has an easy description and high efficiency, and is convenient to implement collateral computations. The main principle is to assume theory of solid annealing, which means heating the solid to desired high temperature, then cools slowly. When heating, particles inside the solid become disorder, inner energy increasing. By contrast, particles become ordered while cooling slowly, and get balance at each temperature, finally reaches ground state at normal temperature while its inner energy diminishes to minimum.

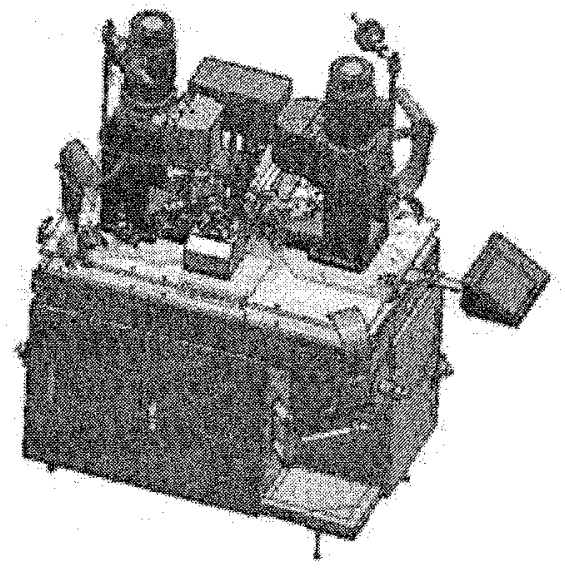

Figure 6. Whole Assembly 
Assume that a machine has $\mathrm{n}$ mechanisms, which are represent by $1-\mathrm{n}$. association between mechanism $i$ and $j$ is $d(i, j)$. We plan to define identity of the heaviest weight mechanism enjoys as our target function. We describe these mechanisms as $\left(w_{1}, w 2, \cdots \cdots \cdot w_{n}\right)$, and $w_{n+1}=w_{1}$

Birth of new solution:

Randomly take $\mathrm{k}$ and $\mathrm{m}$ form $\mathrm{l}-\mathrm{n}, \mathrm{k} \neq \mathrm{m}$. if $\mathrm{k}<\mathrm{m}$, then we change

$\left(\mathrm{w}_{1}, \mathrm{w}_{2}, \cdots \cdots \mathrm{w}_{\mathrm{k}}, \mathrm{w}_{\mathrm{k}+1}, \cdots \cdots, \mathrm{w}_{\mathrm{m}}, \cdots, \mathrm{w}_{\mathrm{n}}\right)$ into:

$\left(w_{1}, w_{2}, \ldots, w_{m}, w_{m-1}, \ldots, w_{k+1}, w_{k}, \ldots, w_{n}\right)$.

If $k>m$, we change $\left(w_{1}, w_{2}, \ldots, w_{k}, w_{k+1}, \ldots, w_{m}, \ldots, w_{n}\right)$

Into $\left(\mathrm{w}_{\mathrm{m}}, \mathrm{w}_{\mathrm{m}-1}, \ldots, \mathrm{w}_{1}, \mathrm{w}_{\mathrm{m}+1}, \ldots, \mathrm{w}_{\mathrm{k}-1}, \mathrm{w}_{\mathrm{n}}, \mathrm{w}_{\mathrm{n}-1}, \ldots, \mathrm{w}_{\mathrm{k}}\right)$.

Through disparate substitution function, we can obtain margin of substitution function, eventually get ID of the most heavy weight mechanism.

Using FPC theory, our full-automatic crimping machine achieves direct success in designing and manufacturing. (See figure 6)

\section{CONCLUSION}

Development of our full-automatic crimping machine combines FPC with various latest bearing fruit in today's international society, with its feature being virtual, digital, network, integrated, intelligent, and green production, flexible manufacturing, synergetic interaction.

Research of Integrated manufacturing/assembly is the distillate of this project. Main assembly designer mark off reasonable function space with advanced CAE analysis method at concept design Emphasis of development of integrated product in FPC lay in manufacturability (including synchronization between designer and technologist, and accept or reject design scheme according to machine cost), feasibility to assemble (in order to assemble easily, we need to use least assembly parts and optimize assembly path. Try to diminish connect constraints as least as possible on the premise that satisfy function requirements), feasibility to corporation (machine without reasonably programming cannot implement anticipated function. Designer of sub-mechanism doesn't only need to take charge of their own design, but also need to make conjunction parts facilitation, humanity.

\section{REFERENCES}

1. You Ying, "Research and Application of key technology in FPC", master thesis, mechanical and electrical engineering school, Wu Han technology university, China, 2004.

2 Integrated Manufacturing Technology Initiative, Inc. First Product Correct.America, 2000 